\title{
Building Sustainability Assessment throughout Multicriteria Decision Making
}

\author{
Lúcio VillarinhoRosa ${ }^{1}$ and Assed Naked Haddad ${ }^{1,2}$ \\ ${ }^{1}$ Universidade Federal Fluminense, Niteóii, RJ, Brazil \\ ${ }^{2}$ Universidade Federal do Rio de Janeiro, Rio de Janeiro, RJ, Brazil \\ Correspondence should be addressed to Assed Naked Haddad; assed@poli.ufrj.br
}

Received 29 May 2013; Revised 16 August 2013; Accepted 16 August 2013

Academic Editor: Fernando Pacheco Torgal

Copyright (c) 2013 L. VillarinhoRosa and A. N. Haddad. This is an open access article distributed under the Creative Commons Attribution License, which permits unrestricted use, distribution, and reproduction in any medium, provided the original work is properly cited.

\begin{abstract}
Opinion and choice strongly influence sustainability concepts. The building construction industry, in particular property developers, has been charged with promoting excess environmental impacts ranging from overuse of resources to pollution generation. This paper presents an application of sustainability concepts to building projects, as well as to the development of practices, methodology, and tools for evaluating existing buildings. This study will detail how current systems to evaluate building performance operate and how to improve them. This approach utilizes the analytic hierarchy process (AHP). AHP is a multicriteria method that evaluates the relative importance of criteria, subcriteria, and families of indicators, used in the proposed system of technical characteristics applied to the local culture. At the same time, AHP makes visible the critical factors involved in evaluation of sustainability of these buildings. A result of the application of this type of modeling is a system for sustainability assessment and evaluation of environmental aspects and socioeconomic perspectives of existing buildings in the state of Rio de Janeiro, Brazil.
\end{abstract}

\section{Introduction}

The term sustainable development has the meaning "emphasis on quality of life," thus enabling people to live in a healthy environment while incorporating continuous improvement of social conditions and economic and environmental issues for the present and future generations [1].

A result of this awareness is that society is considering the construction sector to be a major source of impacts on the environment. This view takes into account the perceived excessive consumption of resources and generation of pollution during the phases of construction and use [2].

Occupancy consumes $80 \%$ of the energy expected to be used throughout the life cycle of a building. Occupancy represents the primary target for actions aimed at energy efficiency to reduce adverse impacts on the environment, human health, and economy [3].

It should be noted that while buildings are large contributors to environmental degradation they are important for the sustainability of business and quality of life, as city dwellers spend $80 \%$ to $90 \%$ of their time indoors $[3,4]$.
At this point, it is important to note that green buildings provide certain outcomes when subjected to specific requirements. These include minimization of disturbances of the ecosystem and other improvements throughout the life cycle as well as optimization of efficiency of resource management and operational performance leading to minimization of risks to human health and the environment [5].

The green building promotes the improvement of the local, regional, and global ecosystem during construction and throughout use and optimizes the efficiency of resource management and operational performance while minimizing risks to human health and the environment $[5,6]$.

This focus on reducing environmental impact creates the need for a tool to enable monitoring outcomes of environmental performance. Such a tool must incorporate a set of verifiable criteria and goals to enable the owners and designers to align themselves with high environmental standards $[2,6]$.

It is worth emphasizing that this endeavor should avoid mere importation of existing methods based on success achieved in developed countries. The reason for this is that 
the central issue in developing countries is to bypass the environmental assessment for assessing the sustainability of buildings. This approach also fails to address the social and economic aspects related to production, operation, and modification of the built environment [7].

The challenge addressed in this paper lies beyond adoption of successful formulas. It is necessary to adapt them to the culture of the country or the importing company $[7,8]$.

This technology transfer is more likely to be successful when proposed as an active and adapted process. This requires participation of knowledgeable personnel in the government and the construction sector [8].

The importance of the construction sector to the economy of Brazil combined with the search for more efficient buildings highlights the priority in building research to develop the means to evaluate the sustainability of new and existing buildings.

The central problem addressed in this paper is to create a method for assessing the sustainability of existing buildings customized for use in Rio de Janeiro. The inputs to be considered include the criteria and subcriteria and the families of indicators and their corresponding relative levels of importance.

\section{Assessment of Sustainability of Buildings}

In 1990, the Building Research Establishment (BRE) in the United Kingdom (UK) developed the first functional method for assessing the environmental performance of buildings. The method was named Building Research Establishment Environmental Assessment Method (BREEAM) [6, 7].

This method contained prescriptive requirements that focused on the interior of the building, its immediate surroundings, and the environment [7].

Since then, many tens of methods were developed and are in use throughout the world. There are basically two approaches for the analysis of environmental performance by buildings $[6,7]$.

The first and most widely used approach builds awards points within a selected number of parameters, so called indicators, according to a scale ranging from a environmental "small impact" to a "huge impact" [9].

These indicators have weights, explicit or not, that recognize the main environmental problems [7, 9-11].

The second model utilizes methodology of Life Cycle Assessment (LCA), to indicate the best choice of design, materials of construction, and options for local utilities. Local utilities include energy supply, waste management, and types of transport [9].

Table 1 shows the weights used for the main categories of evaluation in the most important rating systems used to assess green buildings, namely, Leadership in Energy and Environmental Design (LEED), Technological Research Institute of São Paulo (IPT), Building Research Establishment Environmental Assessment Method (BREEAM), Comprehensive Assessment system for Building Environmental Efficiency (CASBEE), and Sustainable Building Assessment Tool (SBTool) [12-17].
TABLE 1: Comparison between the most important green building rating systems in terms of the weights used in the main categories of evaluation.

\begin{tabular}{lccccc}
\hline \multirow{2}{*}{ Assessment criteria } & \multicolumn{5}{c}{ Green building rating system } \\
& LEED & IPT & BREEAM & CASBEE & SBTool \\
\hline Energy efficiency & $21,7 \%$ & $20,0 \%$ & $8,3 \%$ & $9,6 \%$ & $4,0 \%$ \\
Water efficiency & $7,3 \%$ & $20,0 \%$ & $4,5 \%$ & $9,1 \%$ & $4,0 \%$ \\
$\begin{array}{l}\text { Indoor environment } \\
\text { quality }\end{array}$ & $18,8 \%$ & $6,0 \%$ & $12,4 \%$ & $22,4 \%$ & $23,0 \%$ \\
$\begin{array}{l}\text { Waste and material } \\
\text { management }\end{array}$ & $18,8 \%$ & $20,0 \%$ & $9,8 \%$ & $21,1 \%$ & $12,0 \%$ \\
Eco management & $10,1 \%$ & $0,0 \%$ & $14,1 \%$ & $0,0 \%$ & $10,0 \%$ \\
\hline
\end{tabular}

Most of the tools focus almost exclusively on environmental dimension $[7,9,11]$. The most obvious reason for this type of strategy is the sustainability agenda in the developed countries. This agenda has focused on values intrinsic to the development model. These consider actions seemingly incompatible with each other that have led to a good quality of life simultaneously with those involved with marked elimination of natural resources around the globe [7].

Another reason is the concept of recognizing the right of the "other" that exists in developed countries. Others include neighbors, workers, and neighbourhoods. Collectively, this consideration results in a high level of regulation and democratization in decision making, which is oriented to the production, maintenance, and renewal of the urban built environment $[7,9,11]$.

In contrast to this model, developing countries must address initiatives towards sustainable development, primarily from the perspective of social and economic segments $[7,11]$.

In this sense, several developing countries including Brazil, Jordan, and Taiwan have been working on interventions considering its social and economic contexts involving representatives of the main stakeholders, namely, universities, designers, builders, and users [7, 9-11].

\section{Decision Making}

Decision making is not an action that is required or clearly identifiable. Decision making is a decision process that includes not only the final act of choice between alternatives but also a complete process of decision with four phases: intelligence; design; choice; and review [18, 19].

The decision situations include choice, classification, ordering, ordered classification, and prioritization. Regarding decision situations, they can be described as follows [18].

(a) Choice: selecting an alternative from a set of feasible alternatives.

(b) Classification: classifying viable alternatives into predefined categories.

(c) Ordering: establishing an order of preference for viable alternatives according to a criterion.

(d) Ordered classification: determining the classification of alternatives in preset ordered categories. 
(e) Prioritization: establishing priority order for the elements of a set of alternatives.

Decision making contains at least one of the following characteristics [19].

(a) There are at least two criteria for the solution to the problem, and they conflict with each other.

(b) The alternatives are not well defined, and the consequences of choosing one alternative in relation to the other are not fully understood.

(c) Criteria and alternatives may be interconnected. One criterion may appear to reflect other criteria.

(d) The solution to the problems depends on consensus of a group of people, whose individual viewpoints often conflict.

(e) Some of the criteria are quantifiable, and some require a value judgment assessed on a scale.

(f) Such a scale can be cardinal, ordinal, or verbal, depending on availability of data and nature of the criteria.

Multiple Decision Makers and Concurrent Treatment of Complex Issues are important methods used in Multi Criteria Decision Support in a typical context involving multiple objectives [18].

It is worth noting that these methods consider that even qualitative criteria can be expressed through a numerical scale, and that the value of each alternative proposal indicates its relative position in a ranking $[18,20]$.

Among the more widely used of these methods in various fields of research is the method of Analytic Hierarchy Process (AHP) that provides treatment for complex problems with multiple criteria, stakeholders, and decision makers in a scenario of high uncertainty and high risk [20].

AHP increases the transparency and objectivity of decision making since it functions with multiple agents that can express their preferences, facilitates detection of controversial items, and provides data for the establishment of agreements $[18,21]$.

AHP is a method for choosing the best alternative that incorporates qualitative considerations and quantitative factors into subjective decision making. The theory reflects what seems to be the method of natural functioning of the human mind. That is, when faced with a complex situation with many variables, people gather in groups that share common characteristics $[22,23]$.

\section{The AHP Model}

AHP is based on the use of pairwise comparisons that lead to elaboration of a ratio scale. Moreover, AHP permits refinement of the decision making process while respecting the global coherence of the user's preferences by calculating an overall consistency ratio [18, 22-24].

Construction and use of the AHP model are developed in four stages, namely [18, 23, 24],

(a) structuring the hierarchy in order to identify the main goal, criteria, subcriteria, and alternatives;

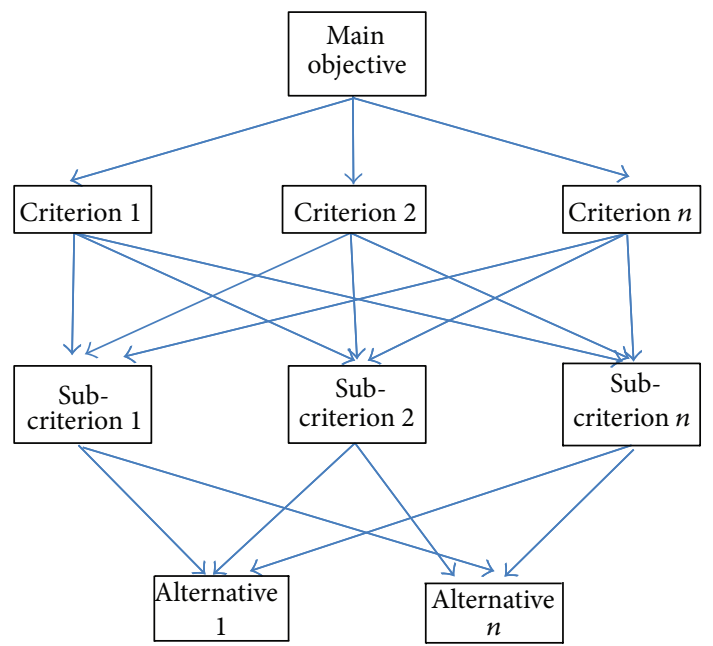

FIGURE 1: Structuring of the hierarchy.

(b) data collection of value judgments issued by experts;

(c) calculating the priority of each alternative;

(d) consistency analysis.

For construction of the hierarchy, starting point of the modeling should contain the following steps, as shown in Figure $1[18,23]$,

(a) Identification of the central purpose or main focus.

(b) Determining the set of criteria, properties, or viewpoints for the evaluation of subcriteria, if any, or alternatives.

(c) Determining the set of subcriteria, if any, for the evaluation of alternatives.

(d) Determining the set of feasible alternatives.

Construction of a hierarchy requires knowledge and experience in the study area and should be performed carefully to represent reliably the problem being treated $[18,20,23]$.

The phase of collecting the value judgments starts following hierarchical structuring of the problem. This phase seeks to answer three main questions [18]: What will be judged? How is this to be judged? And who should judge?

With regard to the first question, the appraiser must conduct a pairwise comparison of the elements on the same layer of the hierarchy viewed from the perspective of elements positioned on the layer immediately above, as shown in Figure $2[18,23]$.

The fundamental scale of judgment proposed by Saaty, creator of the AHP, is shown in Table 2. Nine levels of importance are employed that correspond to the numbers 1 through 9 to rate intensity [23].

Evaluators must have broad knowledge about the study area and some experience concerning value judgments as well. The choice of experts is critical to achievement of good results. This occurs because AHP enables the capture and synthesis of information regardless of whether qualitative or quantitative, tangible or intangible, or subjective or objective present in the minds of those individuals [20]. 


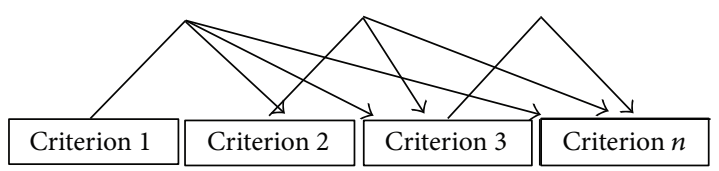

FIGURE 2: The pairwise comparison of the elements of a same layer of the hierarchy.

TABLE 2: The fundamental scale of judgment.

\begin{tabular}{lc}
\hline Verbal scale & Numerical scale \\
\hline Same & 1 \\
Slight & 3 \\
Little & 5 \\
A lot & 7 \\
Extremely & 9 \\
\hline \multicolumn{2}{l}{}
\end{tabular}

Once the structure is built, calculations are then performed to establish prioritization of alternatives. The matrices are then calculated from the lowest level in the hierarchical structure of the AHP framework $[18,23]$.

Utilization of specialists for the realization of value judgments with AHP does not preclude the possibility that these judgments may be inconsistent. AHP allows to evaluate the consistency and extent of inconsistency in a matrix of parity judgment $[18,23]$.

Finally the global valuation of each alternative is performed according to the method of weighted sums [23].

\section{Development of Research}

In what follows are presented the main stages of the research, ordered chronologically. These included

(a) literature review related to sustainability assessment of buildings;

(b) identification of the social, economic, and environmental contexts of the City of Rio de Janeiro;

(c) literature review related to multicriteria analysis;

(d) construction of the hierarchy in AHP;

(e) construction of the scoring model;

(f) case study.

In order to establish the set of variables needed for assessment, buildings sustainability of was analyzed through the main systems. This analysis focused on the possibility of selfassessment by managers of buildings, as well as factors needed to ensure success in implementing the systems in countries at different levels of development [13-17].

Initial work indicated that there are few works related to assessments of sustainability in school buildings. This was a main reason for choice of the theme for the case study [2530].
Another reason for development of the tools described here was to encourage use by students to explore opportunities for improving conditions with regard to the health of the occupants and environmental quality $[25,29]$.

At this point it is worth noting that once the magnitude and speed of growth of the levels of pollution and environmental degradation and depletion of natural resources were recognized, a number of universities agreed to focus on developing solutions to reverse these trends [30].

In 2005, 300 deans, chancellors, and presidents of universities in 40 countries signed a document pledging to take action to address these concerns [30]. Areas of prominence include

(a) establishing programs to develop expertise in environmental management;

(b) encouraging involvement by government, foundations, and industries in support of research in environmental management;

(c) demonstrating examples of environmental responsibility through programs of resource conservation, recycling, and waste reduction in the universities.

In the context of design, construction, and operation of school buildings, several aspects of performance are particularly important in order to fulfil these objectives. These include priority in the use of concepts related to sustainability during design, consideration for sustainability in operation and maintenance, maximizing comfort and safety of occupants, and attention during design of new facilities and expansion and renovation of existing ones to these concepts [29].

The second phase of this work involved field visits to buildings in the state of Rio de Janeiro in order to identify the social, economic, and environmental contexts. This enquiry included first-hand observations and informal interviews with key stakeholders. These individuals included sustainability experts, safety engineers, maintainers, government inspectors, and occupants.

Given the importance of context respecting realities in developing countries, a holistic approach to issues related to sustainability was used to define criteria for evaluating economic, environmental, and social aspects [7, 9, 11,31].

The following grouping of items for verification $[7,9,11$, $13-17,31$ is presented.

(a) Economic aspects: operational investments and operational expenses.

(b) Environmental aspects: eco management, water efficiency, energy efficiency, materials and resources, waste and, pollution, sustainable site.

(c) Social aspects: comfort and health and safety.

Table 3 presents families of indicators for each item previously defined.

The third stage of this project involved bibliographic review related to identifying methodologies for multicriteria analysis culminating with the indication of use of AHP 
TABLE 3: Families of indicators.

\begin{tabular}{|c|c|}
\hline $\begin{array}{l}\text { Items for } \\
\text { verification }\end{array}$ & Families of indicators \\
\hline \multirow{5}{*}{$\begin{array}{l}\text { Operational } \\
\text { investments }\end{array}$} & Annual budget development \\
\hline & Budget plan/actual \\
\hline & Use of automatic systems \\
\hline & Performance planning \\
\hline & Replacement of devices in end of life \\
\hline \multirow{5}{*}{$\begin{array}{l}\text { Operational } \\
\text { expenses }\end{array}$} & Replacement by other similar devices \\
\hline & Budget plan/actual \\
\hline & Development of annual budget timing \\
\hline & Performance planning \\
\hline & Replacement of devices by others more efficient \\
\hline \multirow{3}{*}{$\begin{array}{l}\text { Eco } \\
\text { management }\end{array}$} & Water management system \\
\hline & Waste management system \\
\hline & Energy management system \\
\hline \multirow{5}{*}{$\begin{array}{l}\text { Water } \\
\text { efficiency }\end{array}$} & Water use performance \\
\hline & Innovative reduction water technologies \\
\hline & Water-efficient landscape \\
\hline & Leak detection system \\
\hline & Use of automatic system \\
\hline \multirow{4}{*}{$\begin{array}{l}\text { Energy } \\
\text { efficiency }\end{array}$} & Renewable energy \\
\hline & Use of automatic system \\
\hline & Energy efficient buildings \\
\hline & Innovative reduction energy technologies \\
\hline \multirow{5}{*}{$\begin{array}{l}\text { Materials and } \\
\text { resources }\end{array}$} & Recycle material use \\
\hline & Local and regional materials \\
\hline & Renewable material \\
\hline & Resource reuse \\
\hline & Recycle material collection \\
\hline \multirow{5}{*}{$\begin{array}{l}\text { Waste and } \\
\text { pollution }\end{array}$} & Solid waste production performance \\
\hline & Emission generation performance \\
\hline & $\begin{array}{l}\text { Innovative reduction waste and pollution } \\
\text { technologies }\end{array}$ \\
\hline & Waste water production performance \\
\hline & Other waste production performance \\
\hline \multirow{5}{*}{$\begin{array}{l}\text { Sustainable } \\
\text { site }\end{array}$} & Infrastructure efficiency \\
\hline & Alternative transportation system \\
\hline & Land use \\
\hline & Landscape design \\
\hline & $\begin{array}{l}\text { Relation between the building and its immediate } \\
\text { surroundings }\end{array}$ \\
\hline \multirow{4}{*}{ Comfort } & Thermal comfort \\
\hline & Smell comfort \\
\hline & Visual quality \\
\hline & Acoustic and noise control \\
\hline \multirow{4}{*}{$\begin{array}{l}\text { Health and } \\
\text { safety }\end{array}$} & Indoor air quality performance \\
\hline & Indoor water quality performance \\
\hline & Indoor occupant health quality performance \\
\hline & Indoor occupant safety quality performance \\
\hline
\end{tabular}

for this search. AHP provides a good compromise between targets, understanding, and objectivity [18, 20-22].

The fourth stage was designed to establish the AHP hierarchy as shown in Table 4.

The next stage was reserved for defining the scoring matrix for sustainability assessment (Figure 3 ). The structure involved in deriving the scoring matrix considers the weight and score received by each of the families of indicators under the following possibilities: 0.0 does not meet basic requirements, 0.5 meets basic requirements, and 1.0 exceeds basic requirements [9].

The categorization criteria set out in world-class systems such as LEED, BREEAM, and SBTool based on the percentage of points earned compared to the total possible score in the evaluation provides the basis for the proposed rating of performance in this situation [13-17]:

(a) in search of new paradigms- $80 \%$ to $100 \%$;

(b) sustainable-from $50 \%$ to $79 \%$;

(c) towards sustainability-from $0 \%$ to $49 \%$.

The final stage of this research was the case study. This case study incorporated the concepts discussed and results obtained previously. The focus of the study was a school building, constructed in the 1960s, in the state of Rio de Janeiro.

The first action was to select the experts responsible for the value judgments. Use of judgments from each expert for all categories in the entire AHP hierarchy is not appropriate. The reason is that each individual usually has much knowledge about only a single subject. Hence, they should not be called to participate in assessment of branches of the hierarchy in which they do not have the required knowledge $[18,20]$.

In this project, a single evaluator having the following profile: Professor, Ph.D., Lead Auditor-quality, safety, and environment management systems-, provided value judgments for the criteria in relation to the main objective, as well as the subcriteria in relation to the corresponding criterion [18].

Similar measures were adopted with the appointment of a specialist exclusively for the trial of each family of indicators in relation to the corresponding subcriterion. This involved eleven professionals with extensive experience in civil engineering, electrical engineering, sanitary engineering, environmental management, chemical use, safety, architecture, budget and costs, and management of operations, and maintenance [18].

The procedure for data collection was developed from personal interviews with experts after presentation of the subject in general and the evaluation framework for sustainable buildings in particular [18].

Prior to application of the instrument, the experts were offered the opportunity to provide suggestions for improvement [31].

Every completed questionnaire was subjected to the consistency test, and if found inconsistent, was rejected. In this event, the expert was contacted to request a new contribution $[18,23]$. 
TABLE 4: Matrices of criteria, subcriteria, and alternatives.

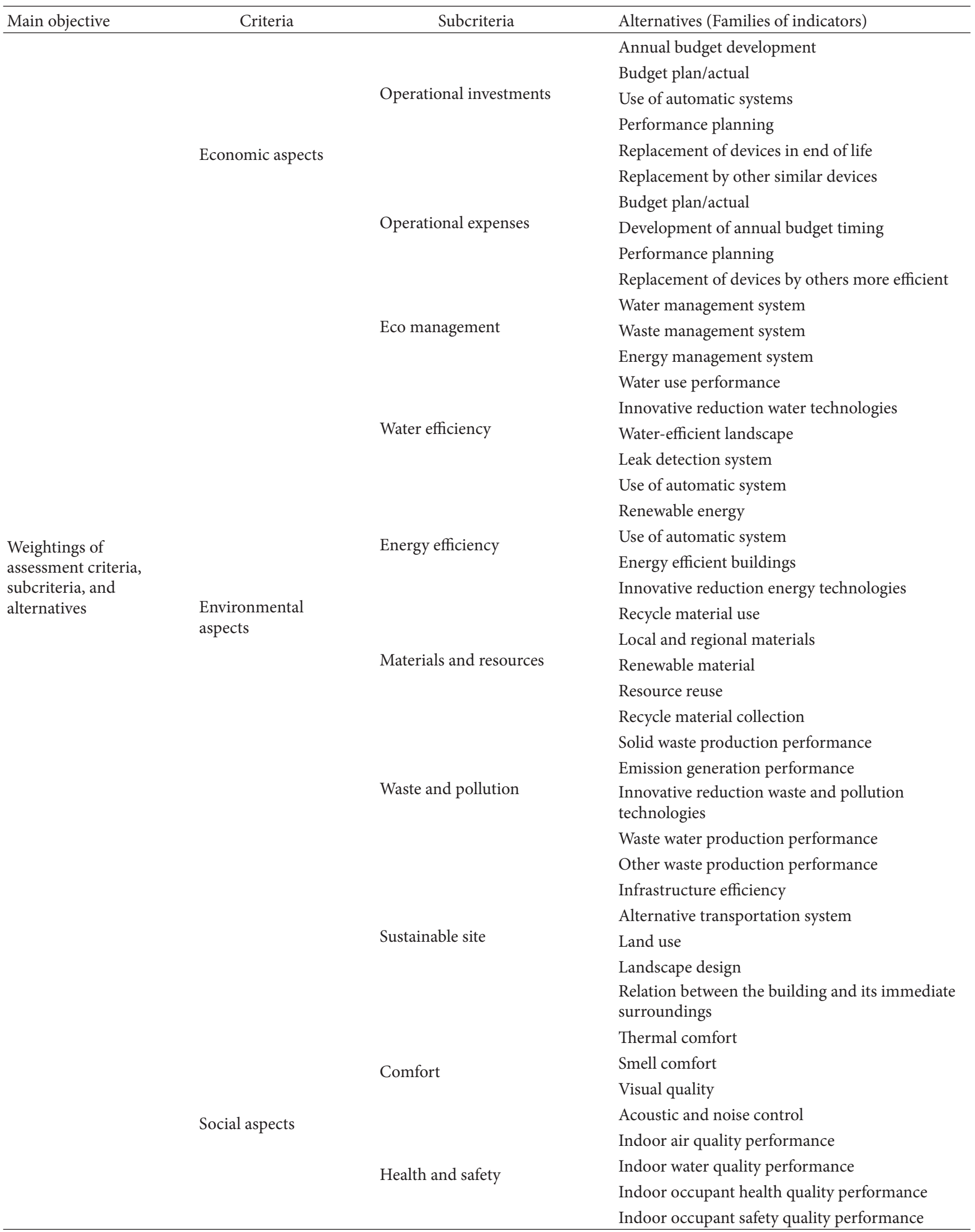




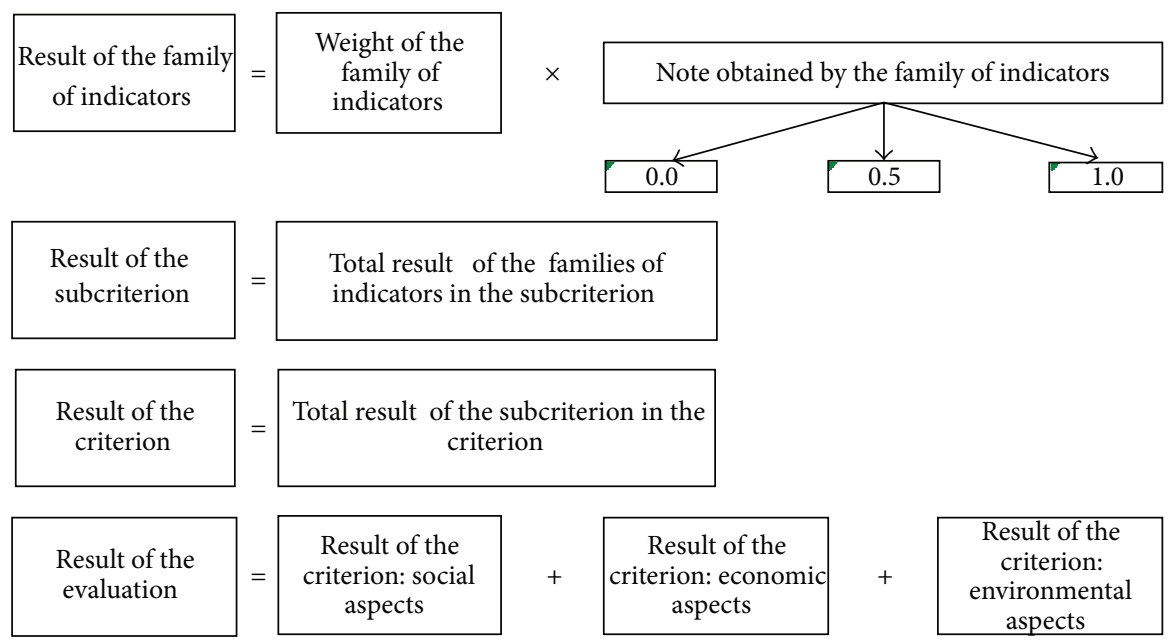

FIGURE 3: Determination of the final result of the evaluation.

TABLE 5: Weightings of assessment criteria and subcriteria.

\begin{tabular}{lll}
\hline Main objective & Criteria & Subcriteria \\
\hline & Economic aspects-43\% & $\begin{array}{l}\text { Operational expenses-21,5\% } \\
\text { Operational investments-21,5\% } \\
\text { Eco management-12,9\% } \\
\text { Water efficiency-15,5\% }\end{array}$ \\
$\begin{array}{ll}\text { Weightings of assessment criteria, subcriteria, and } \\
\text { alternatives-100\% }\end{array}$ & Environmental & Energy efficiency-5,2\% \\
& aspects-43\% & Materials and resources-1,3\% \\
& & Sustainable site-1,7\% \\
& & Health and safety-11,6\% \\
& Social aspects-14\% & Comfort-2,4\% \\
\hline
\end{tabular}

\section{Results Analysis}

Table 5 shows the weighting assigned to criteria and subcriteria.

As can be seen in the first level of the assessment matrix, environmental and economic aspects were ranked at the same importance, each one represents $43 \%$ of the total, and more important than the social aspects representing only $14 \%$.

The lack of importance assigned to social aspects in principle could mean a bad choice in assessing the criteria. In practice, this represents the cultural alignment of the experts who participate in the survey. With the criteria employed by major foreign systems, in the countries of origin, satisfaction of social demands has already occurred [7].

The five subcriteria considered most important are "operational investments", "operational expenses," "water efficiency," "eco management," and "health and safety." These subcriteria show significant distribution in importance among the three criteria employed.

"Use of water" was considered the most important subcriterion in relation to the criterion "environmental aspects." This is evident of a good level of adjustment to the local context consistent with costs and difficulties involved with the systems of water supply in big cities $[7,9,11]$.
TABLE 6: Comparison: main systems (average) X model.

\begin{tabular}{lcc}
\hline Assessment criteria & Model & Main systems \\
\hline Energy efficiency & $5,2 \%$ & $12,7 \%$ \\
Water efficiency & $15,5 \%$ & $8,9 \%$ \\
Indoor environment quality & $14,0 \%$ & $16,5 \%$ \\
Waste and material management & $8,7 \%$ & $16,4 \%$ \\
Eco management & $12,9 \%$ & $11,4 \%$ \\
\hline
\end{tabular}

"Health and safety" in relation to the criterion "social aspects" holds priority over the subcriterion "comfort." This result is expected since the performance of indicators in health and safety sector in Brazil often falls short awakening in the general population a sense of importance and significance.

Table 6 shows the differences obtained in the levels of importance to key aspects of the main systems available compared to the proposed methodology. Only indoor environment quality and eco management have similar level of importance.

Finally, the main tools provide an extensive set of criteria validated in their respective countries and are more efficient 
for an overall evaluation of buildings than for an individualized assessment of a specific project [9].

\section{Conclusions}

Findings obtained during this research indicate that it is possible to assess the sustainability of existing buildings. Sustainability is associated with several environmental, economic, and social aspects that vary from region to region and depend on the prevailing local context $[7,9,11]$.

The holistic approach used in this study produces significant benefits and positive impacts on social and economic areas for developing countries not provided by traditional models used for evaluation. This results because of the heavier emphasis in these models on environmental aspects [7,9].

Another important observation relates to the complex environment of decision making in choosing the criteria, subcriteria, and families of indicators since this occurs in the context of simultaneously acting, multiple variables and personal interpretations of participants reflecting their respective experiences and preferences $[18,23]$.

The multicriteria analysis, implemented with the AHP to determine the relative importance of the aspects involved in a sustainability assessment of existing buildings and supported by the opinion of experts and stakeholders, revealed itself adequate to the extent that the situation demanded a holistic and multidisciplinary perspective [7, 18, 20, 23].

The AHP method eases understanding of the decision making process for the participants involved as well as the meanings of the results $[18,20,23]$.

Use of AHP provides a means to optimize decision making from a quantitative analysis and minimizes impacts associated with the use of purely qualitative methods [18, 23].

Use of specialists with extensive knowledge in specific areas is adequate in view of the reduction in the number of required calculations when employing tools complementary to the AHP to obtain the consensus matrix from arrays of single parity comparisons $[18,32]$.

\section{Conflict of Interests}

The authors would like to state clearly that they did not have any financial relations with any commercial entities and did not mean the research to be influenced by any financial interests.

\section{Acknowledgment}

The authors gratefully acknowledge the assistance of the key actors who participated in the survey.

\section{References}

[1] O. Ortiz, F. Castells, and G. Sonnemann, "Sustainability in the construction industry: a review of recent developments based on LCA," Construction and Building Materials, vol. 23, no. 1, pp. 28-39, 2009.

[2] G. K. C. Ding, "Sustainable construction-the role of environmental assessment tools," Journal of Environmental Management, vol. 86, no. 3, pp. 451-464, 2008.
[3] C. C. Menassa, "Evaluating sustainable retrofits in existing buildings under uncertainty," Energy and Buildings, vol. 43, no. 12, pp. 3576-3583, 2011.

[4] J. Burnett, "City buildings-eco-labels and shades of green!", Landscape and Urban Planning, vol. 83, no. 1, pp. 29-38, 2007.

[5] ASTM Subcommittee E 60.01, American Society for Testing and Materials, E 2114-08-Standard, Terminology for Sustainability Relative to the Performance of Buildings, American Society for Testing and Materials, West Conshohocken, Pa, USA, 2008.

[6] A. Haapio and P. Viitaniemi, "A critical review of building environmental assessment tools," Environmental Impact Assessment Review, vol. 28, no. 7, pp. 469-482, 2008.

[7] V. G. Silva, M. G. Silva, and V. Agopyan, "Evaluation of buildings in Brazil: environmental assessment for the evaluation of sustainability," Built Environment, no. 3, pp. 7-18, 2003.

[8] A. Wisner, "Ergonomics in industrially developing countries," Ergonomics, vol. 28, no. 8, pp. 1213-1224, 1985.

[9] H. H. Ali and S. F. Al Nsairat, "Developing a green building assessment tool for developing countries-case of Jordan," Building and Environment, vol. 44, no. 5, pp. 1053-1064, 2009.

[10] A. Libovich, "Assessing green building for sustainable cities," in Proceedings of the World Sustainable Building Conference (WSBC '05), pp. 1968-1971, Tokyo, Japan, 2005.

[11] J. Gibberd, "Assessing sustainable buildings in developing countries-the Sustainable Building Assessment Tool (SBAT) and the Sustainable Building Lifecycle (SBL)," in Proceedings of the World Sustainable Building Conference (WSBC '05), pp. 16051612, Tokyo, Japan, 2005.

[12] Techne, "Environmental assessment," Pini, no. 133, 2008.

[13] International Initiative for a Sustainable Built Environment (IISBE), "Sustainable Building Assessment Tool (SBTool)," 2012, http://www.iisbe.org/sbmethod-2010.

[14] U.S. Green Building Council, "Leadership in Energy and Environmental Design (LEED)," 2012, http://www.usgbc.org/leed.

[15] Instituto de Pesquisas Tecnologicas do Estado de São Paulo (IPT), "Avaliação do Desempenho Ambiental de Edifícios," 2010, http://www.ipt.br/.

[16] Comprehensive Assessment Sistem for Building Environmental Eficiency (CASBEE), "An overview of casbee," 2012, http://www .ibec.or.jp/CASBEE/english/overviewE.htm.

[17] Building Research Establishment (BRE), "BRE Environmental Assessment Method," 2012, http://www.breeam.org/about .jsp?id=66.

[18] H. G. Costa, Multicriteria Decision Aid-AHP Method, Abepro, Rio de Janeiro, Brazil, 1st edition, 2006.

[19] L. F. A. M. Gomes, M. C. G. Araya, and C. Carignano, Decision Making in Complex Scenarios: Introduction to Discrete Methods of Multicriteria Decision, Pioneira, São Paulo, Brazil, 2004.

[20] C. Parra-López, J. Calatrava-Requena, and T. de-Haro-Giménez, "A multi-criteria evaluation of the environmental performances of conventional, organic and integrated olive-growing systems in the south of Spain based on experts' knowledge," Renewable Agriculture and Food Systems, vol. 22, no. 3, pp. 189203, 2007.

[21] D. N. Tiwari, R. Loof, and G. N. Paudyal, "Environmentaleconomic decision-making in lowland irrigated agriculture using multi-criteria analysis techniques," Agricultural Systems, vol. 60, no. 2, pp. 99-112, 1999.

[22] T. L. Saaty, "How to make a decision: the analytic hierarchy process," European Journal of Operational Research, vol. 48, no. 1, pp. 9-26, 1990. 
[23] T. L. Saaty, The Analytic Hierarchy Process: Planning, Priority Setting, Resource Allocation, McGraw-Hill, 1980.

[24] L.-A. Vidal, E. Sahin, N. Martelli, M. Berhoune, and B. Bonan, "Applying AHP to select drugs to be produced by anticipation in a chemotherapy compounding unit," Expert Systems with Applications, vol. 37, no. 2, pp. 1528-1534, 2010.

[25] U.S. Green Building Council, "The Center for Green Schools," 2012, http://www.centerforgreenschools.org/k12toolkit.

[26] Eco-Schools England, "Environmental Review," 2012, http:// www2.keepbritaintidy.org/ecoschools/gettingstarted/environmentalreview.

[27] Environment Agency-Abu Dhabi Sustainable Schools, "Green School Audit," 2012, http://www.sustainableschools.ae/gsa.aspx.

[28] Ministry of Education, "Green Schools Pilot Initiative," Ministry of Education, Ontario, Canada, 2012, http://www.edu.gov .on.ca/eng/parents/greenschools.html.

[29] British Council for School Environments (BCSE), Sustainable Schools-Getting It Right, 2006.

[30] Association of University Leaders for a Sustainable Future (ULSF), What Is Talloires Declaration?, 2005.

[31] K.-F. Chang, C.-M. Chiang, and P.-C. Chou, "Adapting aspects of GBTool 2005-searching for suitability in Taiwan," Building and Environment, vol. 42, no. 1, pp. 310-316, 2007.

[32] Y. Dong, G. Zhang, W.-C. Hong, and Y. Xu, "Consensus models for AHP group decision making under row geometric mean prioritization method," Decision Support Systems, vol. 49, no. 3, pp. 281-289, 2010. 

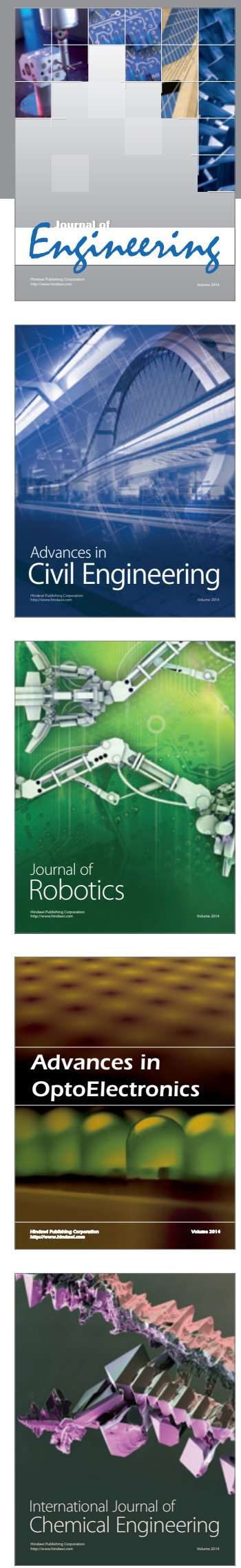

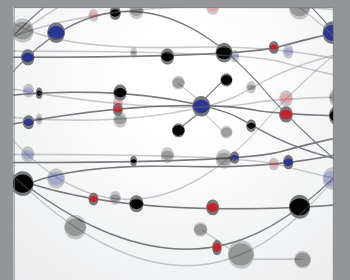

The Scientific World Journal
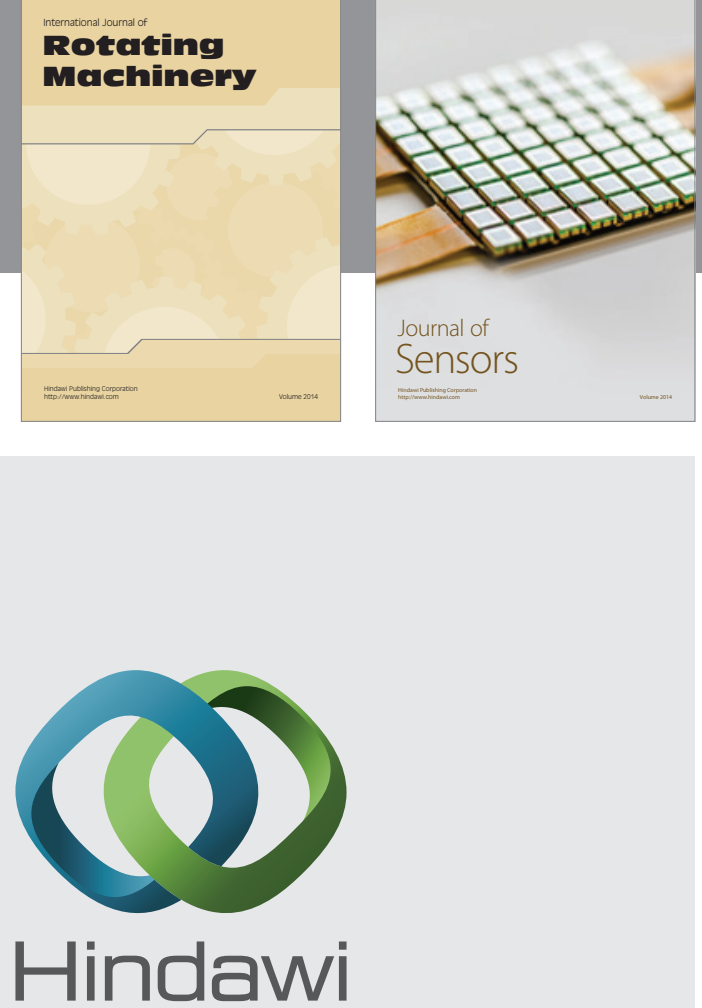

Submit your manuscripts at http://www.hindawi.com
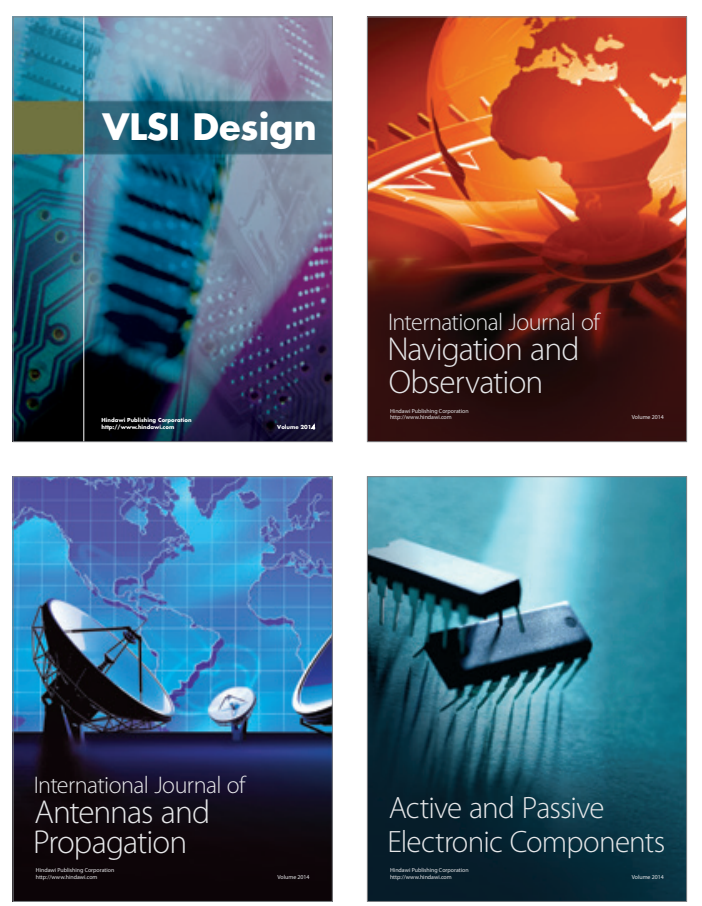
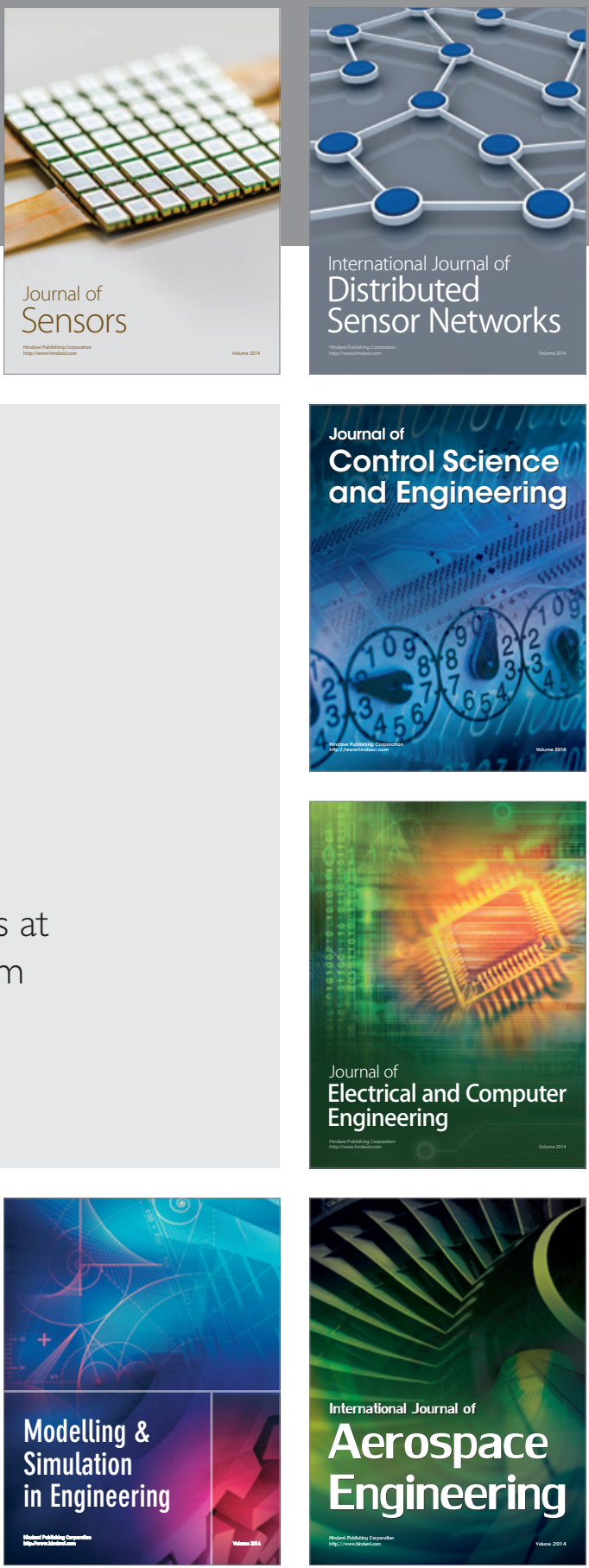

Journal of

Control Science

and Engineering
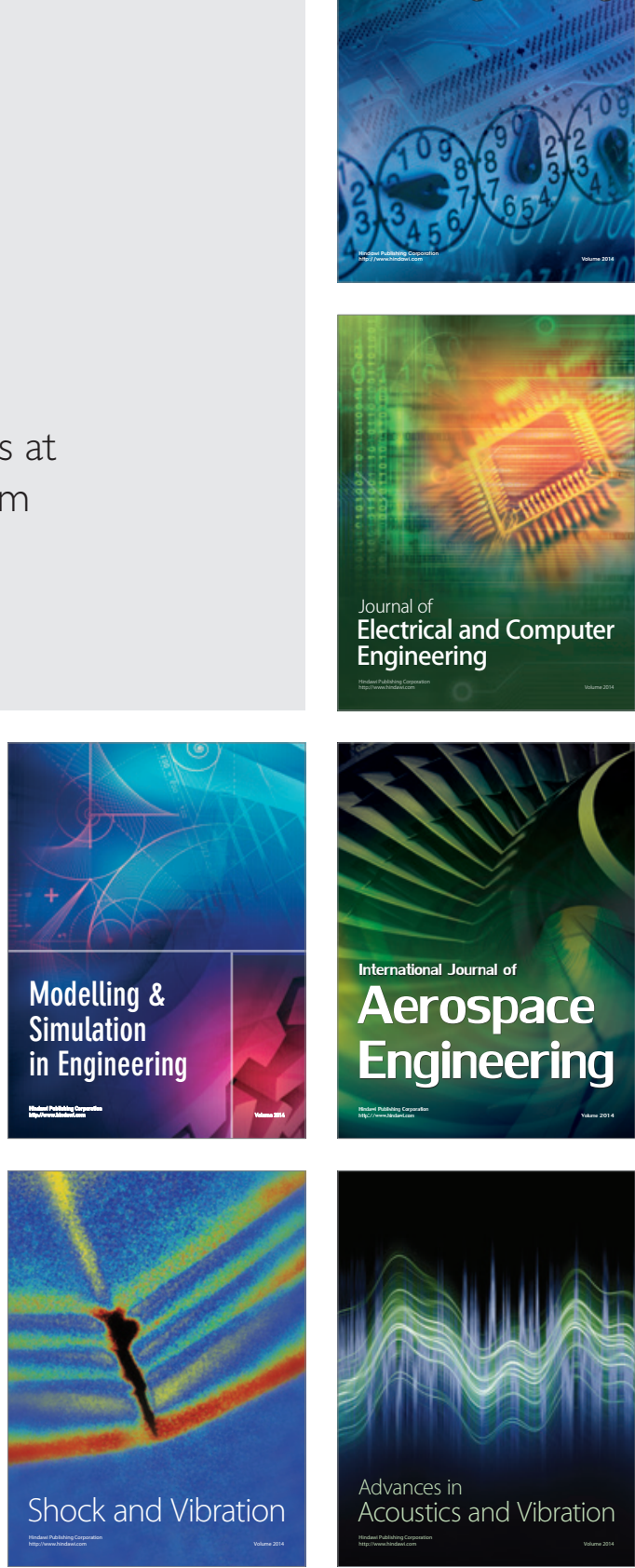